\title{
Effects of Shrinkage Reducing Agent and Expansive Additive on Plastic Shrinkage of Mortar at Different Temperatures
}

\author{
Sarapon Treesuwan ${ }^{1}$, Komsan Maleesee ${ }^{1}$ and Shigeyuki Date ${ }^{2}$ \\ ${ }^{1}$ Department of Civil Engineering, Faculty of Engineering, King Mongkut's Institute of Technology Ladkrabang, Bangkok \\ 10520, Thailand \\ ${ }^{2}$ Department of Civil Engineering, Faculty of Engineering, Tokai University Kanagawa, Japan
}

\begin{abstract}
In the construction, it is inevitable to perform plaster work in hot weather which causes the dehydration and rapid shrinkage on the paste during the early age. This research shows the studies of reducing the plastic shrinkage of mortar during the early age with such additives as the Shrinkage Reducing Agent (SRA), the Expansive Additive (EX), and the Fly Ash (FA) in controlled temperatures at $30{ }^{\circ} \mathrm{C}$ and $40{ }^{\circ} \mathrm{C}$, with relative humidity between $60 \%$ and $70 \%$ according to the ASTM C1579-06 standard, with the strain gauge installed at $0.5 \mathrm{~cm}$.from the surface. The shrinkage rate was measured starting from the Initial Setting Time and every 10 minutes afterwards for 24 hours. The results show that high temperature effects the cracking and how to use different formulas of additive under different circumstances is considerably important. To use only one additive is not sufficient in high temperature. To use the SRA in addition to the EX enhances better expansion than to use only the EX. Moreover, it is recommended to pay close attention in adding large amount of the FA into mortar with the EX and SRA added which extremely enhances the expansion and potential cracking.
\end{abstract}

\section{Introduction}

There are several methods in reducing the shrinkage of mortar. One of the methods is to use such inorganic materials and additives as the Shrinkage Reducing Agent (SRA) and the Expansive Additive (EX) which can be added during the mixing process[1-4]. Different types of additive to be added with the cement give different results depending on such factors as the property and quantity of the cement used, the mixing ratio, and the curing method. Therefore, thorough study on each type of additives and on the manufacturer's instructions is highly recommended because these additives are beneficial when used appropriately. However, the recommended amount may not always suitable for all operations under different circumstances. Hence, tests is needed to be conducted and the amount used should be controlled. The plaster work is commonly done during the day when the temperature is ordinarily high especially for a tropical country where the average temperature is $30^{\circ} \mathrm{C}$ and, in summer, possibly $40^{\circ} \mathrm{C}$ while most tests are conducted at $25^{\circ} \mathrm{C}$, which hardly is in accordance with real construction. The high temperature is one of several important factors that affects the plastic shrinkage which usually occurs during the early age, i.e., within the first 24 hours [5-6], by effecting the cracking on the surface which not only is difficult to repair but also acts upon the long-term durability of the building structure system. According to the standards from the American Concrete Institute (ACI), the Expansive Additives are divided into 3 types: (1) K-type, with anhydrous hauyne $\left(\mathrm{CaO} * \mathrm{Al}_{2} \mathrm{O}_{3} * \mathrm{CaSO}_{4}\right)$ as its basis; (2) M-type, with gypsum $\left(\mathrm{CaSO}_{4}\right)$ as its basis; and (3) Stype, with tricalcium aluminate $\left(\mathrm{C}_{3} \mathrm{~A}\right)$ and gypsum $\left(\mathrm{CaSO}_{4}\right)$ as its bases, while, according to the Japanese Standards, the Expansive Additives are divided into 2 types: (1) C-SA type, which approximates to the K-type according to the ACI standards, producing the ettringite; and (2) $\mathrm{CaO}$ type, with Calcium Oxide $(\mathrm{CaO})$ as its basis, producing Calcium Hydroxide $\left(\mathrm{Ca}(\mathrm{OH})_{2}\right)$. In this experiment, the EX with Calcium Oxide $(\mathrm{CaO})$ was used as the main additive. The EX helps reduce the shrinkage due to such factors as the expansion from water absorption and the forming of pores and crystals during the hydration reaction process[7]. The Shrinkage Reducing Agent (SRA) is a chemical substance that lowers the surface tension by decreasing the capillary stress on the surface of the paste and reserves the inner moisture which helps to reduce the evaporation on the surface, thus, reducing the shrinkage of the paste on the chemical and environmental aspects[-8 9]. The fly ash is the residual material from coal combustion during the electricity generation. It is round, smaller than 1 micrometre to 150 micrometres in size, generally in finer powder form than the cement, with specific gravity between 2.00 and 2.60 . It possesses cementitious property that is called pozzolanic material while other pozzolanic materials generally possesses little 
or no cementitious valuebut will, in finely divided form and in the presence of sufficient moisture, chemically react with calcium hydroxide at ordinary temperatures to form compounds having cementitious properties. The fly ash is therefore considered beneficial as an additive to be added to the cement mixture[10]. Experiments on the plastic shrinkage during the early age and studies on the 3 types of additive are rare. This research thus focuses on the influence of the plastic shrinkage reduction during the early age, i.e., within the first 24 hours, of mortar added with the fly ash, the shrinkage reducing agent (SRA), and the expansive additive (EX) at $30^{\circ} \mathrm{C}$ and $40^{\circ} \mathrm{C}$. The analysis was conducted conforming to the ASTM C1579-06 standard, using the strain gauge to measure the shrinkage near the surface.

\section{Materials and experiments}

\subsection{Materials}

Table 1. shows the materials used in the experiment and Table 2. shows the chemical composition. The ordinary Portland cement $(\mathrm{C})$, the fly ash (FA) Class $\mathrm{C}$ - according to the ASTM C618 standard, the expansive additive (EX) $\mathrm{CaO}$ type of chemical used for shrinkage reduction and the shrinkage reducing agent (SRA) Polyoxyakylene alkyl ether type- Tetraguard ${ }^{\circledR}$ AS20 were used in this experiment along with fine sand prepared in surface-dry, saturated condition with fineness modulus (F.M.) of 3.05, $0.54 \%$ of absorption, and bulk specific gravity of 2.60 .

\subsection{Experiments}

Table 3. shows the mortar mixing ratio. The water to binder(W/B) ratios were 0.7 , the shrinkage reducing agent was used to replace the water at 0 and $2 \%$ for binder. To replace the cement with the EX and FA, the EX was determined to stay unchanged at $15 \%$ which is the recommended maximum amount, while the amount of FA was adjusted in accordance with the amount of the binder left in the composition. The Hobart mixer was used to mix the mortar by mixing the water and admixtures at low speed for 30 seconds before adding the binder using medium speed and adding the sand in 30 seconds before using high speed. The entire mixing duration was determined for 3 minutes.The setting time was determined following the ASTM C807 standard at $30^{\circ} \mathrm{C}$ and the plastic shrinkage was measured following the ASTM C1579-06 standard. The relative humidity was controlled in the range of $60-70 \%$. The shrinkage wasmeasured at $30^{\circ} \mathrm{C}$ and $40^{\circ} \mathrm{C}$ by controlling the heat from the heat lamps with the waterproof strain gauge for cement work applicable for the range of temperatures between $-10{ }^{\circ} \mathrm{C}$ and $70{ }^{\circ} \mathrm{C}$ installed in the middle of the mold above the crack riser at 0.5 centimetre from the surface. The plastic shrinkage was measured and recorded once every 10 miutes for 24 hours starting from the initial setting time. Figure 1 and Figure 2 show the plastic shrinkage measurement

Table 1. Materials and Physical Properties

\begin{tabular}{llccc}
\hline & \multicolumn{1}{c}{ Kind } & Symbol & Specific gravity & Blaine $(\mathrm{cm} 2 / \mathrm{g})$ \\
\hline Cement & Ordinary Portland Cement & $\mathrm{C}$ & 3.15 & 3,400 \\
\multirow{2}{*}{ Inorganic additive } & Fly ash & FA & 2.23 & 3,800 \\
& Expansive additive & EX & 3.16 & 3,450 \\
admixture & Shrinkage reducing agent & SRA & 0.99 & - \\
\hline
\end{tabular}

Table 2. Chemical Compositionof Binders

\begin{tabular}{lcccccccc}
\hline Kind & $\mathrm{SiO}_{2}(\%)$ & $\mathrm{Al}_{2} \mathrm{O}_{3}(\%)$ & $\mathrm{Fe} 2 \mathrm{O}_{3}(\%)$ & $\mathrm{CaO}(\%)$ & $\mathrm{MgO}(\%)$ & $\mathrm{Na}_{2} \mathrm{O}(\%)$ & $\mathrm{K}_{2} \mathrm{O}(\%)$ & $\mathrm{SO}_{3}(\%)$ \\
\hline $\mathrm{C}$ & 21.45 & 4.64 & 3.05 & 64.99 & 0.88 & 0.09 & 0.59 & 2.47 \\
$\mathrm{FA}$ & 24 & 10 & 21.2 & 32.6 & 2.08 & 0.1 & 3.57 & 1.1 \\
$\mathrm{EX}$ & 4.2 & 1.1 & 1 & 74 & 0.51 & - & - & 16.5 \\
\hline
\end{tabular}

Table 3. Mortar Mixing Ratio

\begin{tabular}{cccc}
\hline $\begin{array}{c}\text { W/B } \\
\text { ratio }\end{array}$ & $\begin{array}{c}\text { FA } \\
\text { Replacement } \\
\text { ratio(Bx\%) }\end{array}$ & $\begin{array}{c}\text { EX } \\
\text { Replacement } \\
\text { ratio(Bx\%) }\end{array}$ & $\begin{array}{c}\text { SRA } \\
\text { Dosage } \\
(\mathrm{Bx} \%)\end{array}$ \\
\hline 0.7 & $0,20,40$ & 0,15 & 0,2 \\
\hline
\end{tabular}




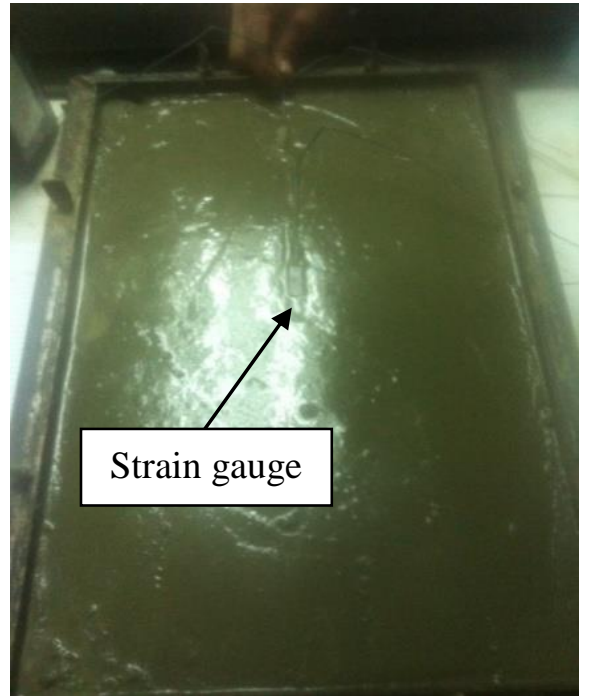

Figure 1. The installation of strain gauge in the middle of the mold at $0.5 \mathrm{~cm}$. from the surface

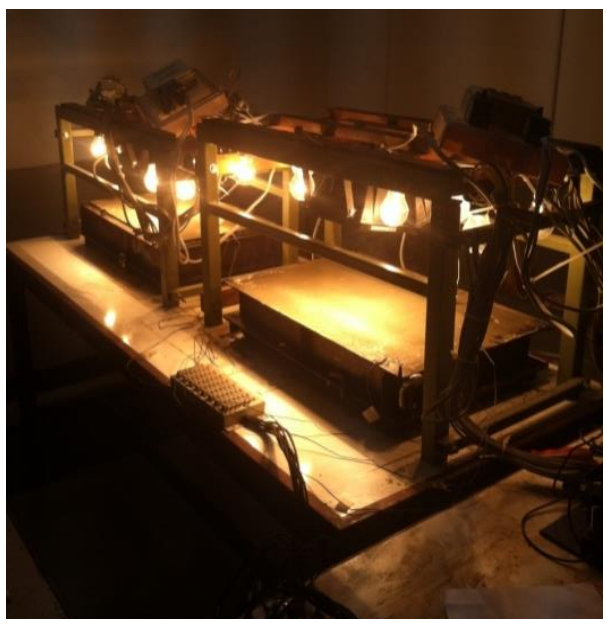

Figure 2. The temperature and relative humidity control for environmental stability according to the experiment plan

\section{Results and discussions}

Figure 3, 4 and 5 show the results of plastic shrinkage during the early age of mortar added with the EX, SRA and $\mathrm{FA}$ at $30^{\circ} \mathrm{C}$ and $40^{\circ} \mathrm{C}$ in comparison with that of the control mortar (C 100\%) 24 hours after molding in accordance with the ASTM C1579-06 standard. The result shows that the shrinkage and expansion rate highly occurs since the initial setting time and the rate decreases after approximately 10 hours after molding. It is obviously seen that, as the temperature rises, the shrinkage rate tends to increase for all formulas of mixture, especially for the control mortar $(\mathrm{C}=100 \%)$ at $40^{\circ} \mathrm{C}$, the risk of cracking is highest in this regard. Mortar with $15 \%$ of EX added expands extremely during the early age at ordinary temperatures. The mortar added with $2 \%$ of SRA extremely reduced the plastic shrinkage both at $30^{\circ} \mathrm{C}$ and at $40^{\circ} \mathrm{C}$ by $24.4 \%$ and $57.6 \%$ respectively after being compared to the control mortar at the same temperature. However, at $40^{\circ} \mathrm{C}$, though the SRA extremely reduced the shrinkage, the measurable plastic shrinkage result was higher than $1000 \mu \varepsilon$. Therefore, there is still a high risk of the cracking on the surface to use only the SRA at high temperature. To add the FA helps to reduce the shrinkage during the early age. The mortar's shrinkage rate decreases in accordance with the increasing ratio of the FA added. This decreasing shrinkage may be the result of the roundness of FA which lessens the water requirement of mortar, causing the excess water on the surface[11-12], resulting the extension of the evaporation period. Moreover, the cement replacement reduces the hydration reaction between the cement and the water which is a cause of the shrinkage[13]. The expansion rate shall increase when the $\mathrm{EX}+\mathrm{SRA}$ are added. This increasing expansion may be the result of the $\mathrm{CaO}$ crystal forming of the EX which normally creates the calcium hydroxide in the form of Hexagonal plate but to add the SRA changes the crystal forming to be in the form of Prismatic needle which is longer in shape[14]. To replace the cement with $15 \%$ of EX $+2 \%$ of SRA and $20 \%$ of the FA does not clearly result in the expansion compared to adding $15 \%$ of $\mathrm{EX}+$ $2 \%$ of SRA but, when $40 \%$ of the FA was replaced, the expansion rate increases for more than $50 \%$ compared to adding $15 \%$ of EX $+2 \%$ of SRA at $25{ }^{\circ} \mathrm{C}$ and at $40{ }^{\circ} \mathrm{C}$ respectively. Nevertheless, care should be taken in terms of compressive strength because the large amount of FA added can reduce the strength during the early age.

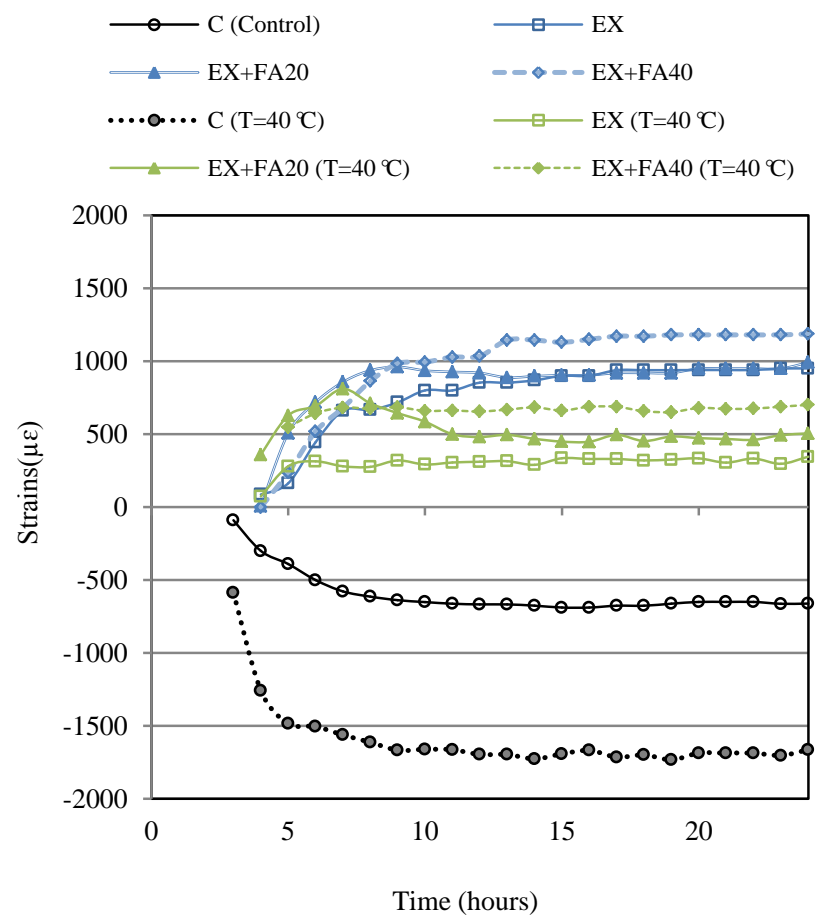

Figure 3. Early age plastic shrinkage results for EX and EX+ FA at $30^{\circ} \mathrm{C}$ and $40^{\circ} \mathrm{C}$ 

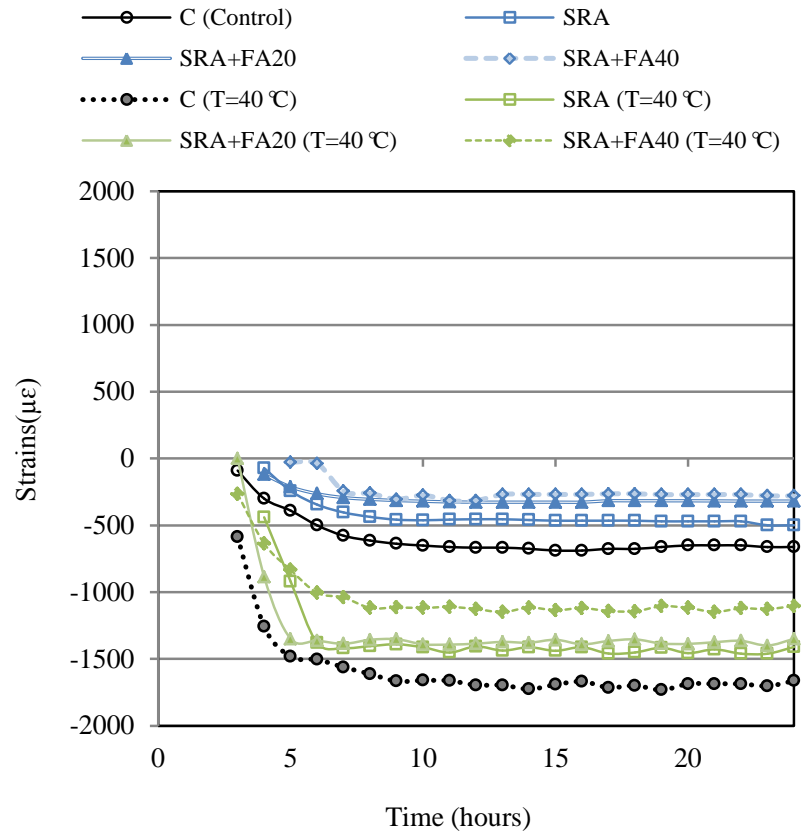

Figure 4. Early age plastic shrinkage results for SRA and SRA $+\mathrm{FA}$ at $30^{\circ} \mathrm{C}$ and $40^{\circ} \mathrm{C}$

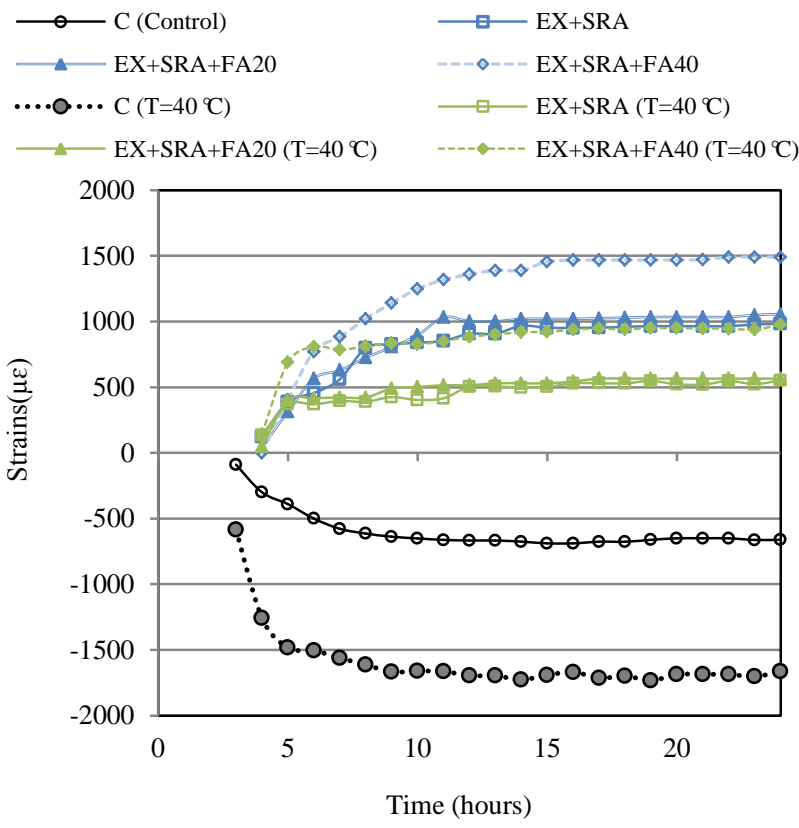

Figure 5. Early age plastic shrinkage results for EX+SRA and $\mathrm{EX}+\mathrm{SRA}+\mathrm{FA}$ at $30^{\circ} \mathrm{C}$ and $40^{\circ} \mathrm{C}$

Figure 6 shows the comparing of plastic shrinkage during the early age of mortar mixed with the FA, EX and SRA at $25^{\circ} \mathrm{C}$ and $40^{\circ} \mathrm{C} 24$ hours after casting according to the ASTM C1579-06. It was obvious that, at higher temperature, the shrinkage amount tended to increase with every mixture, especially with the controlled mortar $\left(100 \%\right.$ cement) at $40^{\circ} \mathrm{C}$, there was a high risk of cracking. As such, to reduce the shrinkage by using the EX, SRA and FA must be considered carefully and used suitably depending on different environments. The shrinkage evaluation during the early age is important especially in high temperature where there is more risk of plastic shrinkage and cracking

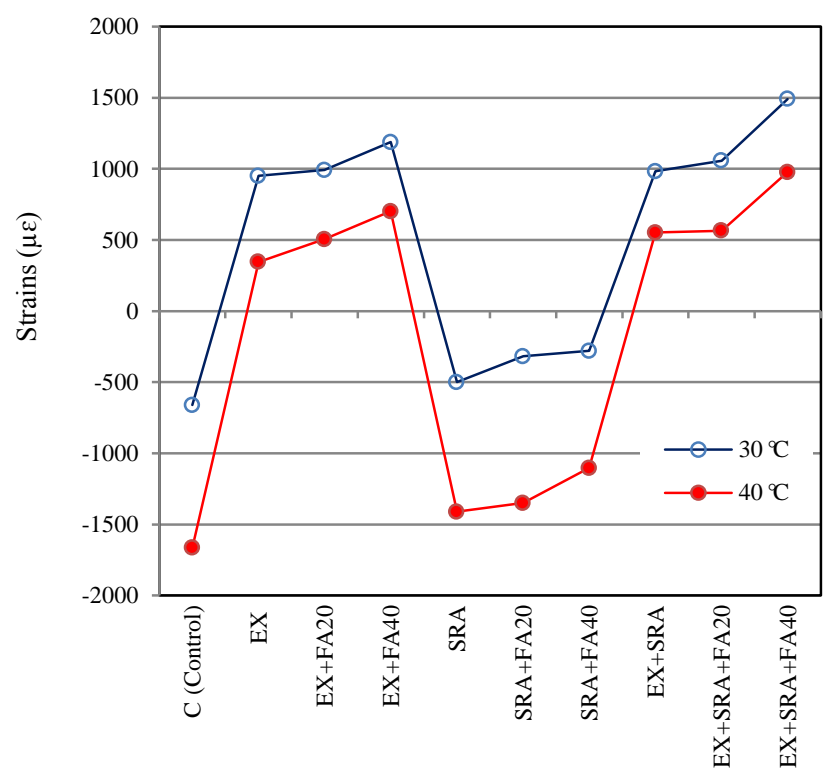

Mix designation

Figure 6. To compare Early-age plastic shrinkage of mortar mixed with FA, EX and SRA at $30^{\circ} \mathrm{C}$ and $40^{\circ} \mathrm{C}$ at $24 \mathrm{hrs}$. after casting

\section{Conclusion}

From the experiment, summaries can be stated as follow.

1) To replace the water with $2 \%$ of SRA helps to reduce the plastic shrinkage in all ranges of temperature but may not be sufficient when the temperature is up to $40{ }^{\circ} \mathrm{C}$ and it helps reducing the shrinkage to add the $\mathrm{SRA}+\mathrm{FA}$ in accordance with higher amount of the FA added.

2) To add $15 \%$ of the EX increases the plastic expansion rate of mortar during the early age, i.e., the expansion rate increases when the ratio of replacing the cement with $\mathrm{FA}$ is raised.

3) To add $15 \%$ of $\mathrm{EX}+2 \%$ of SRA increases the plastic expansion rate of mortar during the early age more than to add only the EX or SRA. The expansion rate extremely rises when the ratio of replacing the cement with FA especially for $40 \%$ is raised.

4) In all formulas of mixture, the plastic shrinkage rate during the early age rises as the temperature changes from $25{ }^{\circ} \mathrm{C}$ to $40{ }^{\circ} \mathrm{C}$.

5) It is recommended to adjust the amount of EX, SRA and FA used in different circumstances to meet the appropriateness as each environmental circumstance differently affects the plastic shrinkage during the early age.

More research is required in different conditions such as steam curing and other properties such as strength and crystalline structure. 


\section{References}

1. Palacios M and Puertas F, Y 2005, Cement and Concrete Research 37 pp 691-702

2. Saliba J, Rozière E, Grondin F and Loukili A, Y 2011, Cement and Concrete Composite 33 pp 209217

3. Carballosa P, García JL, Revuelta D, Sánchez JJ and Gutiérrez JP, Y 2015, Construction and Building Materials 93 pp 223-229

4. Choi H, Lim M, Kitagaki R, Noguchi T and Kim G, Y 2015, Construction and Building Materials 84 pp 468-476

5. Uno P J, Y 1998 ACI Materials Journal, July-August pp 365-375

6. Holt E and Leivo M, Y 2004 Cement \& Concrete Composites 26 pp 521-530

7. Nagataki S and Gomi H, Y 1998 Cement and Concrete Composite 20 pp 163-170
8. Wyrzykowski M, Trtik P, Müncha B, Weiss J, Vontobel P and Lura P, Y 2015 Cement and Concrete Research 73 pp 238-245

9. Bentz D P, Geiker M R and Hansen K K, Y 2001, Cement and Concrete Research 31 pp 1075-1085

10. Chindaprasirt P,JaturapitakkulC and Sinsiri T,Y 2005 Cement \& Concrete Composite 27 pp 425-428

11. Termkhajornkit P, Nawa T, Nakai M, and Saito T, Y 2005, Cement and Concrete Research 36 pp 473-482

12. Nawaz A, Julnipitawong $P$, Krammart $P$, Tangtermsirikul S, Y 2016, Construction and Building Materials 102 pp 515-530

13. Treesuwan S and Maleesee K, Y 2017, Advances in Materials Science and Engineering vol 2017 pp 1-11

14. Maltese C, Pistolesi C, Lolli A, Bravo A, Cerulli T and Salvioni D, Y 2005, Cement and Concrete Research 35 pp 2244-2251 